\title{
A New Technique for Oil Backstreaming Contamination Measurements
}

S.A. Alterovitz and H.J. Speier

Lewis Research Center

Cleveland, Ohio

R.M. Sieg and M.N. Drotos

Cleveland State University

Cleveland, Ohio

and

J.E. Dunning

Michigan State University

East Lansing, Michigan

Prepared for the

38th Annual American Vacuum Society Symposium

Seattle, Washington, November 11-15, 1991

\section{N/Sก}




\title{
A NEW TECHNIQUE FOR OIL BACKSTREAMING
}

\section{CONTAMINATION MEASUREMENTS}

\author{
S.A. Alterovitz and H.J. Speier \\ National Aeronautics and Space Administration \\ Lewis Research Center \\ Cleveland, Ohio 44135 \\ R.M. Sieg ${ }^{*}$ and M.N. Drotos ${ }^{*}$ \\ Cleveland State University \\ Cleveland, Ohio 44115 \\ J.E. Dunning* \\ Michigan State University \\ East Lansing, Michigan 48824
}

\begin{abstract}
Due to the large size and the number of diffusion pumps, space simulation chambers cannot be easily calibrated by the usual test dome method for measuring backstreaming from oil diffusion pumps. In addition, location dependent contamination may be an important parameter of the test. We have measured the backstreaming contamination in the Space Power Facility (SPF) near Sandusky, Ohio, the largest space simulation vacuum test chamber in the U.S.A. We used small size clean silicon wafers as contamination sensors placed at all desired measurement sites. The facility used diffusion pumps with DC 705 oil. The thickness of the contamination oil film was measured using ellipsometry. Since the oil did not wet uniformly the silicon substrate, two analysis models were developed to measure the oil film: (1) Continuous, homogeneous film and (2) Islands of oil with the islands varying in coverage fraction and height. In both cases, the contamination film refractive index was assumed to be that of DC 705 . The second model improved the ellipsometric analysis quality parameter by up to two orders of magnitude, especially for the low coverage cases. Comparison of the two models for our case, shows that the continuous film model overestimates the oil volume by less than 50 percent. Absolute numbers for backstreaming are in good agreement with published results for diffusion pumps. Good agreement was also found between the ellipsometric results and measurements done by x-ray photoelectron spectroscopy (XPS) and by scanning electron microscopy (SEM) on samples exposed to the same vacuum runs.
\end{abstract}

\section{INTRODUCTION}

The Space Power Facility (SPF) near Sandusky, Ohio is the largest vacuum space simulation test chamber in the U.S.A. The SPF was designed to simulate space environment over a wide range of thermal and vacuum conditions for testing advanced propulsion and space power systems. SPF's unique size and high vacuum pumping capacity have facilitated testing of complete space-crafts, two-stage medium weight rockets, and upper atmosphere phenomena with minimal wall effects. The facility is operated by NASA Lewis Research Center. Starting in 1994, the Space Station Freedom (SSF) program will require testing of the SSF electrical power

\footnotetext{
${ }^{*}$ Summer Student Intern at NASA Lewis Research Center.
} 
system hardware in a simulated space environment. The SPF was chosen for the tests. One of the concerns of testing the SSF electrical power system hardware is the possibility of contaminating the test article, with a possible subsequent reduction in performance. One of the very important possible contamination sources is oil backstreaming, especially of diffusion pump oil. However, other contamination sources, both organic (e.g., from lubricants, paints) and inorganic (e.g., dust particles) can also contribute. Due to the large size of the SPF vacuum chamber and possible temperature gradients, the contamination is expected to be location dependent.

This work was initiated to obtain a reliable quantitative estimate of the contamination in the SPF in a space simulation test. The usual method of measuring oil backstreaming, i.e., the test dome method, could not be used due to the chamber size. Several techniques (ref. 1) have been tried, namely ellipsometry, x-ray photoelectron spectroscopy (XPS), residual gas analysis (RGA), non volatile residue (NVR) wipe samples and scanning electron microscopy (SEM). This paper will report in detail the results obtained by ellipsometry. This technique gave location dependent quantitative results which were in qualitative agreement with the XPS and SEM data. To date, the other two methods (RGA and NVR) were not pursued beyond the initial tests and were not used in the final contamination estimate.

The paper is divided into three parts: experimental, results, and discussion. A short description of the SPF and the ellipsometric technique will be given in the experimental part. The second part describes the results obtained using two ellipsometric models, namely the island and the continuous film models, as function of position. The last part includes a discussion of the two models for analyzing the ellipsometric data, and an evaluation of ellipsometry versus the other techniques used in the SPF contamination experiments.

\section{EXPERIMENTAL}

The Space Power Facility (SPF) vacuum chamber has a 100-ft (30.5-m) diameter and a 121 -ft $(36.9-\mathrm{m})$ height. It offers the user $800000 \mathrm{ft}^{3}\left(22653.477 \mathrm{~m}^{3}\right)$ of usable unobstructed volume. The vacuum system consists of thirty two 48 -in. diameter liquid nitrogen (LN) baffled diffusion pumps mounted in the chamber floor. The diffusion pumps are backed by a five-stage roughing train consisting of four stages of roots blowers in series and a single stage of three rotary-piston type mechanical vacuum pumps in parallel. Under dry, clean, empty conditions, the chamber will achieve a pressure of $10^{-7}$ torr. The pumpdowns conducted during this test program yielded a chamber pressure of $5 \times 10^{-6}$ torr without complete LN flow to the baffles. The samples for ellipsometry consisted of small clean silicon wafers that were positioned at a variety of locations inside the vacuum chamber. Commercial silicon wafers were cut into roughly $1-$ by $1-\mathrm{cm}$ pieces and were thoroughly cleaned for possible organic and inorganic contamination using the following procedure: boiling trichloroethylene, boiling acetone, boiling methanol, $30 \mathrm{sec}$ dip in 1:10 $\mathrm{HF}$ : $\mathrm{H}_{2} \mathrm{O}$ and rinse with deionized water. These silicon pieces will be named slides in this paper. For each vacuum pumpdown, slides were located within $2 \mathrm{ft}$ of each diffusion pump and at eight other locations throughout the chamber, at different orientations and distances from the diffusion pumps.

The ellipsometer used in this work is a variable angle spectroscopic unit that was described previously and will not be repeated here (ref. 2). For a detailed description of ellipsometry, see reference 3 . The instrument measures changes in the polarization of 
monochromatic light upon reflection from the sample in terms of the ellipsometric parameters $\psi_{\mathrm{e}}$ and $\Delta_{\mathrm{e}}\left(\right.$ or $\tan \psi_{\mathrm{e}}$ and $\left.\cos \Delta_{\mathrm{e}}\right)$. Here $\psi_{\mathrm{e}}$ and $\Delta_{\mathrm{e}}$ are defined by

$$
\tan \psi_{e^{e}} e^{i \Delta}=\frac{R_{p}}{R_{s}}
$$

where $R_{p}$ and $R_{s}$ are the complex effective reflection coefficients for light polarized parallel and perpendicular to the plane of incidence, respectively. The measurement of $\psi_{\mathrm{e}}, \Delta_{\mathrm{e}}$ is repeated at a variety of wavelengths (in the range of 3200 to $7500 \AA$ ) and angles of incidence $\left(\operatorname{mostly} 75^{\circ}\right.$ ). The usual method of estimating the thicknesses $d_{j}$ of one or more overlayers on a substrate when the complex refractive index of all the films and the substrate are known consist of two steps. First, $R_{p}$ and $R_{s}$ are calculated (ref. 3 ) assuming continuous, homogeneous films with interfaces parallel to each other and to the substrate. Using equation (1), calculated values $\psi_{c}, \Delta_{c}$ are estimated. In the second step, a least square minimization procedure is used to find the values of $d_{j}$ that minimize the function

$$
\sigma=(\mathrm{N}-\mathrm{P})^{-1} \Sigma_{1}\left[\left(\tan \psi_{\mathrm{e}, \mathrm{i}}-\tan \psi_{\mathrm{c}, \mathrm{i}}\right)^{2}+\left(\cos \Delta_{\mathrm{c}, \mathrm{i}}-\cos \Delta_{\mathrm{c}, \mathrm{i}}\right)^{2}\right]
$$

The summation is over all $\mathrm{N}$ experimental points, i.e., all wavelengths and angles of incidence. $P$ is the number of free parameters, $d_{j}$ in this case. In the oil contamination work, several slides, unexposed to the vacuum, were used as reference. They were analyzed in terms of crystalline $\mathrm{Si}(\mathrm{c}-\mathrm{Si})$ with a $\mathrm{SiO}_{2}$ overlayer, using published results for the complex refractive index versus wavelength (refs. 4 and 5). We obtained $\mathrm{SiO}_{2}$ thicknesses in the range of 22 to $34 \AA$, but the values of $\sigma$ were higher than expected for a perfect $\mathrm{SiO}_{2}$ film. However, we used this structure as the composite substrate in all our analyses, as it was not the accuracy limiting factor in this study. The oil contaminated samples were analyzed in two ways. First, we assumed a continuous oil film and used the procedure outlined above to find the thickness of this layer on top of the composite substrate. The oil used in the diffusion pumps was Dow Corning 705 (DC 705), which according to the published data (ref. 6) has a refractive index of 1.579. This oil has very small absorption in the wavelength range of 3200 to $7500 \AA$ used here (ref. 7), and thus the constant 1.579 value was used. Some of the results showed very poor fits to this simple model with rather large $\sigma$ values. In parallel, a scanning electron microscope (SEM) was used to observe the morphology of the contaminated samples. The SEM pictures show a discontinuous coverage of the slides. Thus, a second ellipsometric model was used, namely the islands model (refs. 8 and 9). A detailed discussion of the conditions required for the application of this model to the oil contamination problem as compared to the more common (ref. 10) effective medium approximation (EMA) will be given elsewhere. We found that the EMA model is not applicable in this particular case. In the island model, the reflected light from the overlayer covered composite substrate and the bare surface are superimposed in a coherent way, i.e.,

$$
R_{\nu}=f R_{\nu, c}+(1-f) R_{\nu, b}
$$

Here $\nu=\mathrm{p}$ or $\mathrm{s}$ polarizations, $\mathrm{R}_{\nu, \mathrm{c}}$ and $\mathrm{R}_{\nu, \mathrm{b}}$ are the reflection coefficients for the covered and bare surface respectively, and $\mathrm{f}^{\prime}$ is the fraction of the surface covered by the overlayer. 


\section{RESULTS}

Four pumpdowns were performed, with the following durations in hours: 28, 74, 100, and 72. Silicon slides were located at 39 points in the SPF vacuum chamber for each one of the 28,74 , and $72 \mathrm{hr}$ runs, and at 12 points for the $100 \mathrm{hr}$ run. The 32 diffusion pumps were divided into two groups: 16 in the north group and 16 in the south group. Besides the 32 slides located by the diffusion pumps, 7 others were located at important points in the chamber, e.g., east and west doors, top center, crane, RGA location and others. An example of the way results were summarized is given in table I. The example shows the ellipsometric analysis results for the 32 slides located by the 32 diffusion pumps: slides 1 to 16 are in the south side group and slides 17 to 32 are in the north side group. Besides the pump number, the table has the following columns: the continuous film trigonometric mean square errors (trig MSE) $\sigma$, and thicknesses $\mathrm{d}$; and the islands model results, namely the trig MSE $\sigma$, the average island height $t$, the island coverage fraction $f$, and the parameter $t \cdot f$. The $t \cdot f$ parameter, measured in angstroms, is the equivalent oil thickness obtained in the islands model, and should be compared with the continuous film thickness $d$. We will use the $t \cdot f$ parameter as an effective oil thickness throughout this paper. The table clearly shows that the values of $\sigma$ for the continuous film model are higher by up to two orders of magnitude as compared to those obtained using the islands model. However, above $\mathrm{f}=0.70$, the islands model converges into the continuous film model, giving almost the same $\sigma$ values. A graph of the $\sigma$ (trig MSE) values versus the islands fraction for the samples in table I is given in figure 1. It shows that the islands model gives good fits to the experimental data at all coverage fractions $\mathrm{f}$, but the quality of the fits is really excellent for $\mathrm{f}$ values at or below approximately 0.10 , with $\sigma$ at or below $10^{-3}$. These excellent fits were also obtained for the $28 \mathrm{hr}$ run where all 39 samples had $\mathrm{f} \leq 0.10$. In this short run, the islands model $\sigma$ values were in the range $4 \times 10^{-5} \leq \sigma \leq 2.5 \times 10^{-4}$. For comparison, the continuous film model for the $28 \mathrm{hr}$ run gave the range $3 \times 10^{-4} \leq \sigma \leq 1.7 \times 10^{-2}$. A more detailed quantitative comparison of the two models used here will be given elsewhere (ref. 10).

A SEM picture of one of the slides (No. 32 in table I) is given in figure 2. Several important results were obtained from the SEM picture:

(1) Oil contamination gives a discontinuous film that covers the substrate in the form of disconnected islands.

(2) The coverage value obtained by ellipsometry $(0.114)$ is in good agreement with a visual estimate of 0.1 .

(3) The ideal islands model is not completely applicable, as a small part of the islands start to wet the substrate and/or do not maintain their original shape.

We repeated the SEM work on some of the slides several months later, and the number of broken up islands grew considerably. In addition, most of the higher coverage samples have a larger percentage of nonideal island morphology. This fact explains the higher values of $\sigma$ obtained for these samples, as shown in figure 1.

Practical application of this method for discontinuous film effective thickness measurement will be enhanced if a simpler model is used. Many ellipsometers can measure the thickness of one continuous film. In figure 3 we compare the results of the effective thickness $t \cdot f$ measured in the $72 \mathrm{hr}$ "proof of performance" run versus the results for the thickness $\mathrm{d}$ obtained from the 
continuous film analysis on the same slides. We can clearly see two regimes: large and small thicknesses, and a crossover. As expected, at very high coverage fractions, i.e., near the continuous film regime with $\mathrm{f} \geq 0.70$, corresponding to films with thicknesses d over $220 \AA$, the slope of the curve approaches 1 . This result is reinforced by another measurement. In addition to the work on the SPF, we tested other vacuum chambers. In one of these tests, highly contaminated samples show continuous film coverage. For example, one sample had the following results: continuous film model $\mathrm{d}=229.1 \AA$ and $\sigma=2.5 \times 10^{-5}$, islands model $\mathrm{t}=228.2 \AA, \mathrm{f}=1.008$ and $\sigma=2.4 \times 10^{-5}$. In this case, the islands model is clearly not needed, although it converges to the correct answer, and it corresponds to a slope of 1 in figure 3 . The small thicknesses regime in figure 3 corresponds to small coverage fractions and to a more ideal islands structure. Figure 3 clearly shows a linear dependence of $t \cdot f$ on $d$, for $d<100 \AA$. We also examined the $t \cdot f$ versus $d$ relationship for the $28 \mathrm{hr}$ run and the result is shown in figure 4. A completely linear dependence was obtained, with a slope of 0.77 and a correlation coefficient of 0.990 showing excellent linearity. As will be shown in the discussion part, this result is only applicable for oil contamination work using our experimental 3200 to $7500 \AA$ wavelength range.

Other observations obtained from analyzing the ellipsometric results were:

(1) The slides from the $28 \mathrm{hr}$ run had the thinnest films of all four pumpdowns. This run gave an average t.f value of $15.7 \AA$ versus thicknesses of over $150 \AA$ for other runs. In addition, this run has also the lowest contamination rate.

(2) The south side diffusion pumps slides show more contamination than the north side group. For example, in the $72 \mathrm{hr}$ run, the south side pumps have an average t.f value of $184 \AA$ versus only $118 \AA$ for the north side group.

(3) The oil films thicknesses decrease as the distance from the diffusion pump increases. For example, in the $72 \mathrm{hr}$ run, the slides by the diffusion pumps have a $151 \AA$ average thickness versus only $34.2 \AA$ for the other seven slides.

(4) Backstreaming rate was calculated directly from the thickness of the oil films on the slides by the diffusion pumps, the length of the run and the oil density (ref. 6). For the three long runs an average backstreaming value of $0.37 \times 10^{-6} \mathrm{mg} / \mathrm{cm}^{2} / \mathrm{min}$ was obtained. In contrast, the short $28 \mathrm{hr}$ run gave only $0.1 \times 10^{-6} \mathrm{mg} / \mathrm{cm}^{2} / \mathrm{min}$ backstreaming rate.

\section{DISCUSSION}

This part is divided in two main sections: (1) Comparison of ellipsometry to other oil contamination characterization methods used in the SPF calibration work (ref. 1), and its applicability for backstreaming estimates and (2) Discussion on the applicability of the continuous film results to quantitative oil contamination analysis.

Comparison of the ellipsometry work with SEM results was already discussed.

Comparison with XPS is rather complex, as XPS is an excellent technique for characterizing the type of contaminant, but not as good in estimating the depth of the film. Ellipsometry and XPS are complementary techniques. In the SPF work, the conclusions from the XPS analysis (ref. 11) compared to ellipsometry were the following: 
(1) The oil contamination is probably DC 705, as Si peaks were observed. In the ellipsometry work we used this result, i.e., it was an assumption.

(2) For all samples, both the substrate and the silicon oil contamination were observed simultaneously, by XPS, denoting incomplete coverage. In ellipsometry, the island model gave much better fits than the continuous film model, pointing to the same result.

(3) The short $28 \mathrm{hr}$ run gave almost undetectable silicon oil by XPS. Ellipsometry gave an average thickness (i.e., t.f value) of $15.7 \AA$ for the slides near the diffusion pumps, and $7.4 \AA$ for other locations, accompanied by a very small $(f \leq 0.10)$ coverage.

(4) The presence of silicon oil contamination by XPS decreased as distance from the diffusion pumps increased. This result was also found by ellipsometry, as reported in the "results" part.

(5) XPS shows that the south diffusion pump group gave more silicon oil contamination than the north group. This result was also found by ellipsometry, and it was consistent, i.e., it was measured for all four pumpdowns. Even in the case of the $28 \mathrm{hr}$ run, the south group had an average thickness (i.e., t.f value) of $19.7 \AA$ and the north group only $11.7 \AA$. Thus, an excellent agreement was found between XPS, SEM, and ellipsometry: XPS gave more information on the type of contamination, SEM showed the island type morphology and ellipsometry gave the effective thickness and, thus, the backstreaming rate.

The backstreaming calculated from the ellipsometrically determined film thicknesses $t \cdot f$ will now be compared with published data obtained for oil diffusion pumps using DC 705 and baffles. The present average result of $0.4 \times 10^{-6} \mathrm{mg} / \mathrm{cm}^{2} / \mathrm{min}$ is lower than the value $5.3 \times 10^{-6} \mathrm{mg} / \mathrm{cm}^{2} / \mathrm{min}$ reported by Hablanian (ref. 12) on a 6-in. diffusion pump, but is in excellent agreement with the results obtained by Langdon and Fochtman (ref. 13). In reference 14, a chevron-baffled diffusion pump gave backstreaming values in the range 0.1 to $1.0 \mathrm{mg} / \mathrm{cm}^{2} / \mathrm{min}$, with most of the pumpdowns giving values around $0.5 \mathrm{mg} / \mathrm{cm}^{2} / \mathrm{min}$. The SPF also uses chevron baffled diffusion pumps.

We will now discuss the general applicability of the results shown in figures 3 and 4 . We checked the universality of the experimental slope (0.77) found in figure 4 using a simulation. Assuming an ideal oil island model, we calculated $\psi_{\mathrm{c}}$ and $\Delta_{\mathrm{c}}$ in the wavelength range 3200 to $7500 \AA$ for films with different values of $\mathrm{t}(300 \AA \leq \mathrm{t} \leq 500 \AA)$ and $\mathrm{f}(0.02 \leq \mathrm{f} \leq 0.15)$, on top of a $22 \AA \mathrm{SiO}_{2}$ on c-Si substrate. From these $\psi_{\mathrm{c}}, \Delta_{\mathrm{c}}$ values we calculated, using a least square fit, the thickness $\mathrm{d}$ of a continuous oil film and the accompanying $\sigma$. We obtained a completely linear $t \cdot f$ dependence on $d$, with a slope of 0.74 and a correlation coefficient of 0.9999 for the linear fit. The values of the calculated $\sigma$ changed in a similar way to the experimental ones, i.e., increasing very fast with increasing coverage fraction $f$. This comparison with theory again shows that our oil contamination samples with low values of $f$, are closely described by the ideal island model. However, the calculated value of 0.74 for the slope is not universal. We recalculated the same $t \cdot f$ versus $d$ dependence by simulation, using two wavelength ranges: 3200 to $5300 \AA$, and 5301 to $7500 \AA$. We found only approximate linear dependencies, with slopes of roughly 1.1 and 0.5 for the two wavelength ranges respectively and for $\mathrm{f} \leq 0.1$. In conclusion, generally the continuous film model gives only a rough approximation for the value of the effective oil thickness, and probably an error by a factor of 2 is possible for low coverage fractions. However, for our experimental range, the continuous film approximation is much better, and errors are smaller than $\mathbf{5 0}$ percent. 
We will now comment on the anomalous low $t \cdot f$ values for two points in figure 3 . These points have continuous film thicknesses $d$ near $300 \AA$. These two points correspond to coverage fractions of 0.51 and 0.38 , whereas all other points with $d>240 \AA$ have $f \geq 0.78$. This result shows that in the $f$ range around 0.5 , the $t \cdot f$ versus $d$ graph depends also on $f$. It turns out that the north and south diffusion pump groups gave slightly different types of islands, with the north group average island height of $429 \AA$ (standard deviation $86 \AA$ ), while the south group had an average $t=365 \AA$ (standard deviation $107 \AA$ ). Thus, the two groups do not have the same morphology versus thickness, and the crossover between the island model and the continuous film occurs at different values of the continuous film thicknesses.

\section{CONCLUSIONS}

A new technique for measuring oil backstreaming and other contamination in large vacuum chambers was demonstrated, namely ellipsometry. This technique can measure thicknesses of both continuous films of contaminants as well as discontinuous, island type of deposits. This last type was found in the DC 705 oil backstreaming experiment in the SPF. In either case, an a-priori knowledge of the (complex) refractive index of the contaminants is required. This method is quantitative and it shows excellent agreement with results obtained by XPS and SEM. For an accurate determination of the contamination, the islands model is required. However, relatively good estimates of backstreaming can be obtained by the simplest ellipsometric model of a single continuous contamination film.

\section{ACKNOWLEDGMENT}

We would like to thank Ms. N. Bogner for part of the data analysis and for typing the manuscript.

\section{REFERENCES}

1. Speier, H.J.: Backstreaming Analysis Report of SPF During the Period May 21, 1990 to July 27, 1990. Preliminary Information Report No. 250, Space Station Freedom Directorate, NASA Lewis Research Center, Cleveland, OH.

2. Alterovitz, S.A., et al.: Optical Dispersion Relations for Diamondlike Carbon Films. Optical Materials: Processing and Science, D.B. Poker and C. Ortiz, eds., Mater. Res. Soc. Symp. Proc. Vol. 152, Materials Research Society, 1989, pp. 21-26.

3. Azzam, R.M.A.; and Bashara, N.M.: Ellipsometry and Polarized Light. North Holland Publishing, 1977.

4. Aspnes, D.E.; and Studna, A.A.: Dielectric Functions and Optical Parameters of Si, Ge, $\mathrm{GaP}, \mathrm{GaAs}, \mathrm{GaSb}$, InP, InAs, and InSb, From 1.5 to 6.0 Ev. Phys. Rev. B, vol. 27, no. 2, 1983, pp. 985-1009.

5. Malitson, I.H.: Interspecimen Comparison of Refractive Index of Fused Silica. J. Opt. Soc. Am., vol. 55, no. 10, pt. 1, 1965, pp. 1205-1209. 
6. Crawley, D.J.; Tolmie, E.D.; and Huntress, A.R.: Evaluation of a New Silicone Fluid for Diffusion Pumps. Transactions of the Ninth National Vacuum Symposium, G.H. Bancroft, ed., MacMillan, 1962, pp. 399-403.

7. Kroes, R.L.: Photoluminescence and Optical Transmission of Diffusion-Pump Oils. Appl. Opt., vol. 12, no. 9, 1973, pp. 2075-2078.

8. Muller, R.H.; and Farmer, J.C.: Macroscopic Optical Model for the Ellipsometry of an Underpotential Deposit - Lead on Copper and Silver. Surf. Sci., vol. 135, no. 1-3, 1983, pp. 521-531.

9. Armstrong, M.J.; and Muller, R.H.: Island Films Resulting from Ion-Bombardment Spectroscopic Ellipsometry and Auger Electron Spectroscopy. J. Appl. Phys., vol. 65, no. 8, 1989, pp. 3056-3060.

10. Aspnes, D.E.; Theeten, J.B.; and Hottier, F.: Investigation of Effective Medium Models of Microscopic Surface Roughness by Spectroscopic Ellipsometry. Phys. Rev. B, vol. 20, no. 8,1979 , pp. 3292-3302.

11. Speier, H.J.: Backstreaming Analysis Report of SPF During the Period May 21, 1990 to July 27, 1990. Preliminary Information Report No. 250, appendix B, Space Station Freedom Directorate, NASA Lewis Research Center, Cleveland, OH.

12. Hablanian, M.H.: Backstreaming Measurements Above Liquid-Nitrogen Traps. J. Vac. Sci. Technol., vol. 6, no. 1, 1969, pp. 265-268.

13. Langdon, W.M.; and Fochtman, E.G.: Backstreaming in Baffled Systems. Transactions of the Tenth National Vacuum Symposium, G.H. Bancroft, ed., MacMillan Book Co., 1963, pp. 128-133. 
TABLE I. - ELLIPSOMETRICALLY DETERMINED OIL CONTAMINATION OF ALL DIFFUSION PUMPS IN THE SPF, USING TWO ANALYSIS METHODS

\begin{tabular}{|c|c|c|c|c|c|c|}
\hline \multirow{2}{*}{$\begin{array}{c}\text { Pump } \\
\text { number }\end{array}$} & \multicolumn{2}{|c|}{ Continuous film } & \multicolumn{4}{|c|}{ Islands model } \\
\cline { 2 - 7 } & $\sigma$, & $\mathrm{d}$, & $\sigma$, & $\mathrm{t}$, & $\mathrm{f}$ & $\mathrm{t} \cdot \mathrm{f}$ \\
& $10^{-2}$ & $\AA$ & $10^{-2}$ & $\AA$ & & $\AA$ \\
\hline 1 & 0.626 & 220 & 0.316 & 268 & 0.7070 & 189.3 \\
2 & 3.18 & 55.5 & .023 & 562 & .0743 & 41.73 \\
3 & .167 & 301 & .083 & 322 & .8948 & 287.8 \\
4 & .439 & 338 & .427 & 347 & .9552 & 331.4 \\
5 & .178 & 240 & .112 & 259 & .8759 & 226.7 \\
6 & 3.64 & 72.4 & .029 & 524 & .1002 & 52.46 \\
7 & .133 & 366 & .088 & 383 & .9349 & 357.6 \\
8 & 1.56 & 256 & 1.41 & 286 & .8061 & 230.8 \\
9 & 1.38 & 88.9 & .039 & 312 & .2066 & 64.48 \\
10 & 1.10 & 113 & .025 & 276 & .3043 & 83.93 \\
11 & 4.19 & 137 & .132 & 453 & .2049 & 92.86 \\
12 & 2.24 & 193 & 1.19 & 335 & .3959 & 132.7 \\
13 & 1.23 & 282 & .937 & 322 & .7761 & 249.8 \\
14 & 1.14 & 284 & 1.14 & 289 & .9681 & 279.3 \\
15 & .746 & 282 & .550 & 314 & .8206 & 257.9 \\
16 & 5.66 & 90.2 & .094 & 586 & .1106 & 64.77 \\
17 & 1.70 & 34.6 & .029 & 597 & .0448 & 26.75 \\
18 & 5.03 & 101 & .503 & 542 & .1284 & 69.59 \\
19 & 2.60 & 287 & 1.06 & 401 & .5119 & 205.3 \\
20 & 3.97 & 279 & 1.12 & 465 & .3795 & 176.5 \\
21 & 5.61 & 199 & .643 & 511 & .2469 & 126.2 \\
22 & .467 & 366 & .175 & 411 & .8406 & 345.5 \\
23 & 6.53 & 207 & 1.10 & 538 & .2343 & 126.0 \\
24 & 7.24 & 152 & .805 & 576 & .1690 & 97.34 \\
25 & 1.52 & 95.8 & .162 & 323 & .2115 & 68.31 \\
26 & .444 & 310 & .283 & 339 & .8589 & 291.2 \\
27 & 6.76 & 141 & .767 & 563 & .1628 & 91.66 \\
28 & 2.00 & 39.2 & .042 & 602 & .0498 & 29.98 \\
29 & 2.73 & 55.9 & .052 & 545 & .0762 & 41.53 \\
30 & 3.47 & 84.8 & .400 & 491 & .1201 & 58.97 \\
31 & 4.51 & 116 & .677 & 464 & .1570 & 77.56 \\
32 & 3.08 & 78.4 & .358 & 484 & .1139 & 55.13 \\
\hline
\end{tabular}




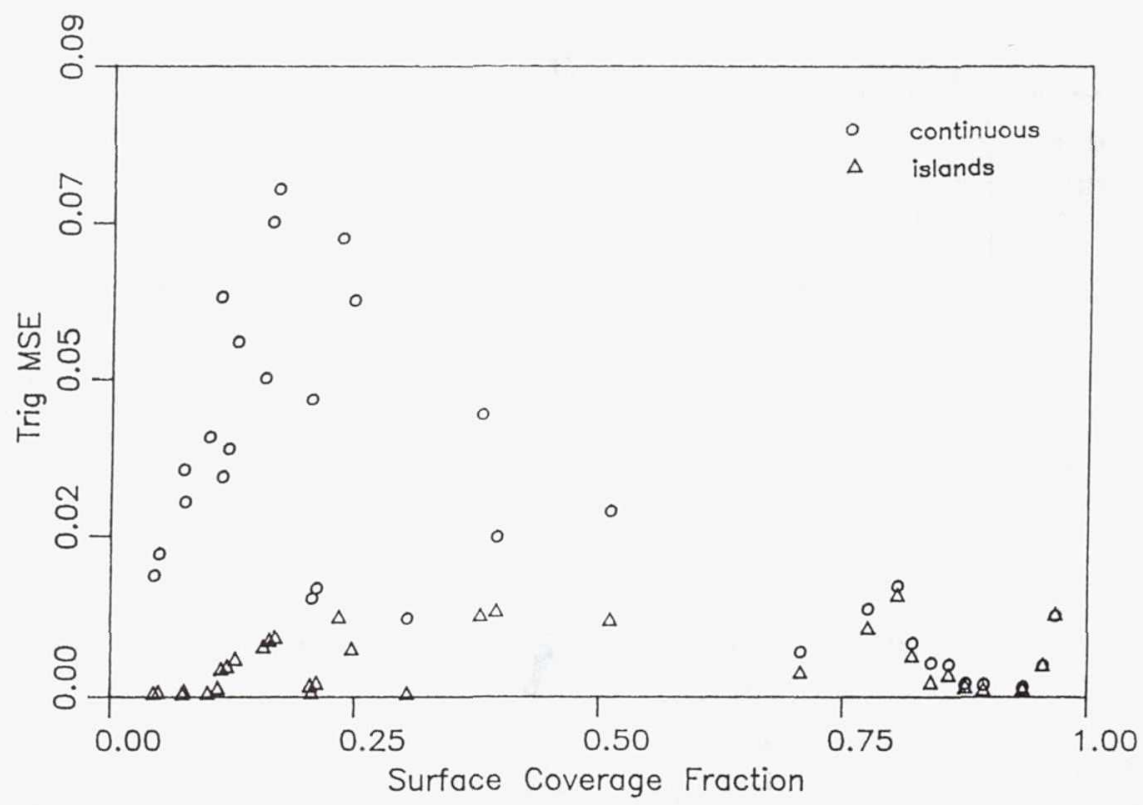

Figure 1.-Trigonometric mean square error (trig. MSE) $\boldsymbol{\sigma}$ versus the islands coverage fraction $f$ obtained using the continuous film and the islands model, for the slides given in Table I.

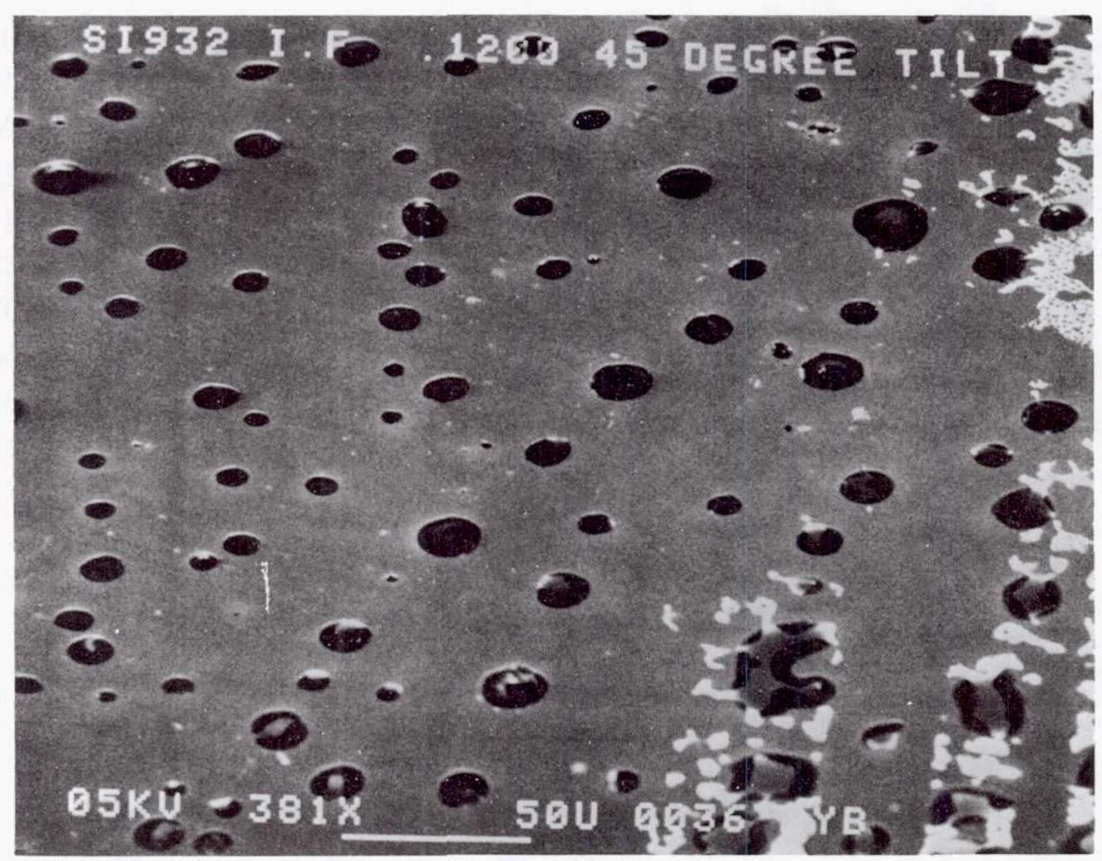

Figure 2.-Scanning electron microscope (SEM) picture of an oil contaminated slide showing the islands' structure. 


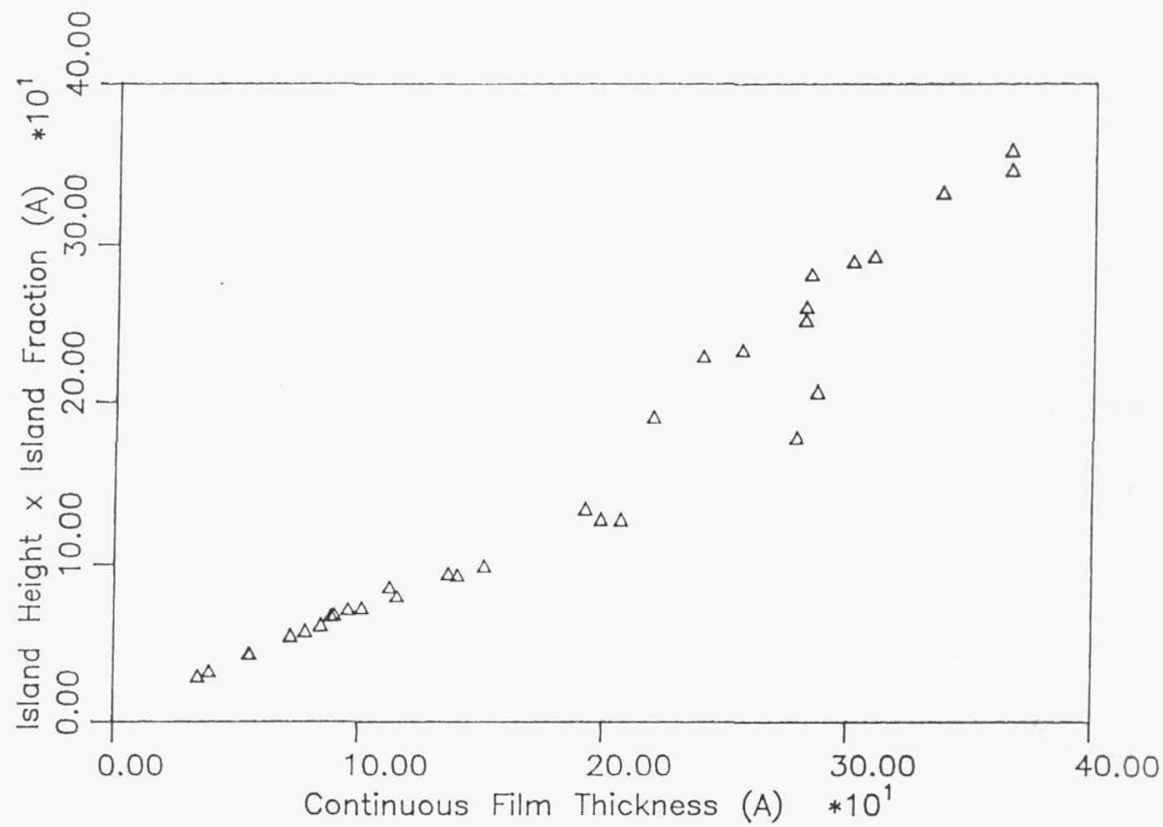

Figure 3.-The effective thickness $\mathrm{ft}$ as determined from the islands model versus the continuous film model thickness $d$ for the 72 hours run.

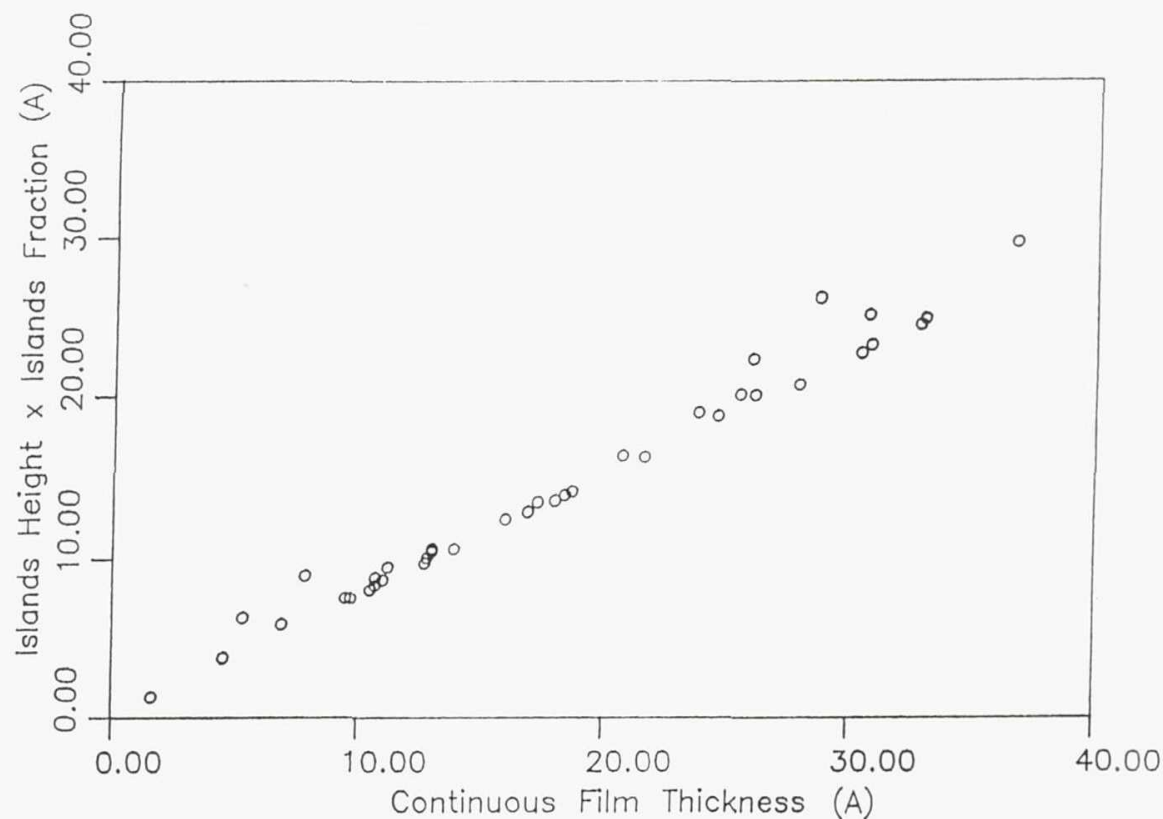

Figure 4.-The effective thickness $\mathrm{ft}$ as determined from the islands model versus the continuous film model thickness $d$ for the 28 hours run. 
Public reporting burden for this collection of information is estimated to average 1 hour per response, including the time for reviewing instructions, searching existing data sources, gathering and maintaining the data needed, and completing and reviewing the collection of information. Send comments regarding this burden estimate or any other aspect of this collection of information, including suggestions for reducing this burden, to Washington Headquarters Services, Directorate for information Operations and Reports, 1215 Davis Highway, Suite 1204, Arlington, VA 22202-4302, and to the Office of Management and Budget, Paperwork Reduction Project (0704-0188), Washington, DC 20503.

\begin{tabular}{|l|l|l}
\hline 1. AGENCY USE ONLY (Leave blank) & $\begin{array}{c}\text { 2. REPORT DATE } \\
1991\end{array}$ & $\begin{array}{r}\text { 3. REPORT TYPE AND DATES COVERED } \\
\text { Technical Memorandum }\end{array}$ \\
\hline
\end{tabular}

\section{TITLE AND SUBTITLE}

5. FUNDING NUMBERS

A New Technique for Oil Backstreaming Contamination Measurements

6. AUTHOR(S)

WU-506-44-21

S.A. Alterovitz, H.J. Speier, R.M. Sieg, M.N. Drotos, and J.E. Dunning

\section{PERFORMING ORGANIZATION NAME(S) AND ADDRESS(ES)}

National Aeronautics and Space Administration

Lewis Research Center

Cleveland, Ohio 44135 - 3191
8. PERFORMING ORGANIZATION REPORT NUMBER

E-6665

\section{SPONSORING/MONITORING AGENCY NAMES(S) AND ADDRESS(ES)}

National Aeronautics and Space Administration

Washington, D.C. 20546-0001
10. SPONSORING/MONITORING AGENCY REPORT NUMBER

NASA TM-105312

\section{SUPPLEMENTARY NOTES}

Prepared for the 38th Annual American Vacuum Society Symposium, Seattle, Washington, November 11-15, 1991. S.A. Alterovitz and H.J. Speier, NASA Lewis Research Center; R.M. Sieg and M.N. Drotos, Cleveland State University, Cleveland, Ohio 44115 and Summer Student Interns at NASA Lewis Research Center; J.E. Dunning, Michigan State University, East Lansing, Michigan 48824 and Summer Student Intern at NASA Lewis Research Center. Responsible person, S.A. Alterovitz, (216) 433-3517.

12a. DISTRIBUTION/AVAILABILITY STATEMENT 12b. DISTRIBUTION CODE

Unclassified-Unlimited

Subject Category 74

13. ABSTRACT (Maximum 200 words)

Due to the large size and the number of diffusion pumps, space simulation chambers cannot be easily calibrated by the usual test dome method for measuring backstreaming from oil diffusion pumps. In addition, location dependent contamination may be an important parameter of the test. We have measured the backstreaming contamination in the Space Power Facility (SPF) near Sandusky, Ohio, the largest space simulation vacuum test chamber in the U.S.A. We used small size clean silicon wafers as contamination sensors placed at all desired measurement sites. The facility used diffusion pumps with DC 705 oil. The thickness of the contamination oil film was measured using ellipsometry. Since the oil did not wet uniformly the silicon substrate, two analysis models were developed to measure the oil film: (1) Continuous, homogeneous film and (2) Islands of oil with the islands varying in coverage fraction and height. In both cases, the contamination film refractive index was assumed to be that of DC 705. The second model improved the ellipsometric analysis quality parameter by up to two orders of magnitude, especially for the low coverage cases. Comparison of the two models for our case, shows that the continuous film model overestimates the oil volume by less than 50 percent. Absolute numbers for backstreaming are in good agreement with published results for diffusion pumps. Good agreement was also found between the ellipsometric results and measurements done by x-ray photoelectron spectroscopy (XPS) and by scanning electron microscopy (SEM) on samples exposed to the same vacuum runs.

\section{SUBJECT TERMS}

High vacuum orbital simulator; Ellipsometers

\begin{tabular}{l|c}
\hline $\begin{array}{l}\text { 17. SECURITY CLASSIFICATION } \\
\text { OF REPORT }\end{array}$ & $\begin{array}{c}\text { 18. SECURITY CLASSIFICATION } \\
\text { OF THIS PAGE } \\
\text { Unclassified }\end{array}$ \\
\begin{tabular}{l} 
Unclassified \\
\hline
\end{tabular}
\end{tabular}

NSN 7540-01-280-5500

\section{SECURITY CLASSIFICATION} OF ABSTRACT Unclassified

\section{LIMITATION OF ABSTRACT}


National Aeronautics and Space Administration

Lewis Research Center

Cleveland, Ohio 44135

Official Business

Penalty for Private Use $\$ 300$
Postage and Fees Paid National Aeronautics and Space Administration NASA 451 